\title{
CORRESPONDENCE
}

\section{Clinical Practice Guideline: The Prevention and Treatment of Obesity}

by Prof. Dr. med. Alfred Wirth, Prof. Dr. med. Martin Wabitsch, Prof. Dr. med. Hans Hauner in issue 42/2014

\section{Telemedicine-Based Treatment}

Given that obesity continues to be a pressing health problem, the "Prevention and Treatment of Obesity" guideline (1) prepared by Wirth, Wabitsch and Hauner is very commendable. Based on a literature search for the period 2005 to 2012, the guideline describes the possibilities and limitations of the conventional treatment approaches (dietary therapy, exercise therapy and bariatric surgery).

Unfortunately, the authors overlooked an innovative, telemedicine-based treatment supported by not only one but two controlled and randomized studies published between 2010 and 2012 (2, 3). Another extensive and controlled study about this method has been published this year (4). The Magdeburg University Hospital's multimodal "Active Body Control" (ABC) program combines dual nutrition with continuous exercise monitoring and regular personalized online support (www.abcprogramm.de).

With weight reductions of $9 \mathrm{~kg}$ and $11.6 \mathrm{~kg}$ after 3 months and 12 months, respectively, the ABC program achieved significantly greater weight loss than the conventional methods discussed in the guideline (4-6 kg for dietary therapy; 2-3 kg for exercise therapy, and $5.5 \mathrm{~kg}$ for the multimodal M.O.B.L.I.S program). By leveraging new technologies, the time required by patients and their coaches is significantly reduced compared with other German programs, as are the drop-out rates (0 to $18 \%$ ). In the meantime, three German health insurances have agreed to (in some cases significantly) subsidize participation in the $\mathrm{ABC}$ program.

Given these favorable and well published data, the $\mathrm{ABC}$ program should be adequately represented in the guideline, too.

DOl: 10.3238/arztebl.2015.0250a

\section{REFERENCES}

1. Wirth $A$, Wabitsch $M$, Hauner $\mathrm{H}$ : Clinical practice guideline: The prevention and treatment of obesity. Dtsch Arztebl Int 2014; 111: 705-13.

2. Luley C, Blaik A, Aronica S, Dierkes J, Kropf S, Westphal S: Evaluation of three new strategies to fight obesity in families. J Nutr Metab 2010: 751905.

3. Luley C, Blaik A, Reschke K, Klose S, Westphal S: Weight loss in obese patients with type 2 diabetes: effects of telemonitoring plus a diet combination- the Active Body Control (ABC) Program. Diabetes Res Clin Pract 2011; 91: 286-92.

4. Luley C, Blaik A, Götz A, et al.: Weight loss by telemonitoring of nutrition and physical activity in Patients with metabolic syndrome for 1 year. J Am Coll Nutr 2014; 33: 363-74.

Prof. Dr. med. Claus Luley

Institut für Klinische Chemie und Pathobiochemie,

Klinikum der Otto-von-Guericke-Universität, Magdeburg

claus.luley@med.ovgu.de

Conflict of interest statement

Prof. Luley has developed the ABC program at the Magdeburg University Hospital.

When Aipermon stopped the production of Aipermotion activity sensors, Prof. Luley acquired the equipment inventory, distribution and support.

\section{In Reply:}

Prof. Luley rightly points out that telephone- and internet-based intervention programs are available for overweight and obese patients. Besides face-to-face programs, telemonitoring interventions represent another weight reduction option to support people living in rural areas, especially if they are younger.

The full version of the guideline (www.adipositasgesellschaft.de) mentions Internet- and telephone-based weight loss programs, referring to two articles published in 2012. The guideline in Deutsches Ärzteblatt is - as stated there-a short version (1).

However, for several reasons, discussed in a recent systematic review of 7 randomized and controlled studies (2), Internet- and telephone-based programs are not recommended in the full version of the guideline either. The authors arrived at the conclusion that mobile technology-based programs can achieve good shortterm and moderate mid-term results. Yet, the guideline requires long-term success ( $\geq 1$ year). In addition, the authors noted deficits of the available studies with regard to clinical standards (diet, exercise), evidence of cost effectiveness and patient acceptance, and concluded that further studies in this field are needed.

The literature search for the guideline was completed in 2013. At that time, an analysis of 6-month data from the ABC program of 2011 was available; one-year data were published online in August 2014. The program was not mentioned in the guideline for the following reason: "At the time of printing of the guideline, 12-month evaluation data from Internet-based weight loss programs in Germany were not available."

DOl: $10.3238 / a r z t e b l .2015 .0250 b$

\section{REFERENCES}

1. Wirth A, Wabitsch M, Hauner H: Clinical practice guideline: The prevention and treatment of obesity. Dtsch Arztebl Int 2014; 111: 705-13.

2. Bacigalupo R, Cudd P, C Littlewoo, et al.: Interventions employing mobile technology for overweight and obesity: an early systematic review or randomized controlled trials. Obesity reviews 2013; 14: 279-91.

\section{Prof. Dr. med. Alfred Wirth}

Bad Rothenfelde

wirthbr@t-online.de

Prof. Dr. med. Martin Wabitsch

Klinik für Kinder- und Jugendmedizin,

Sektion Pädiatrische Endokrinologie und Diabetologie,

Universität UIm

Prof. Dr. med. Hans Hauner

Klinikum rechts der Isar,

Technische Universität München,

Else-Kröner-Fresenius-Zentrum für Ernährungsmedizin,

München

\section{Conflict of interest statement}

Prof. Hauner has received consultancy fees from Weight Watchers International and Apothecom (advisory boards). He has received third-party funding from Weight Watchers International and from Riemser $\mathrm{GmbH}$ and Certmedica. He is a member of an international advisory board of NovoNordisk.

Prof. Wirth has received consultancy fees from Riemser $\mathrm{GmbH}$.

Prof. Wabitschhas has received consultancy fees from Johnson and Johnson MEDICAL $\mathrm{GmbH}$. 